\title{
Effects of Compound-326, a Selective Delta-5 Desaturase Inhibitor, in ApoE Knockout Mice with Two Different Protocols for Atherosclerosis Development
}

\author{
Hiroki Nagase ${ }^{1}$, Shuichi Takagahara ${ }^{1}$, Yoshinori Satomi ${ }^{2}$, Ayumi Ando $^{2}$, Kazuki Kubo ${ }^{1}$, Shota Ikeda ${ }^{1}$ \\ ${ }^{1}$ Cardiovascular and Metabolic Drug Discovery Unit and ${ }^{2}$ Integrated Technology Research Laboratories, Pharmaceutical \\ Research Division, Takeda Pharmaceutical Company Limited, 26-1, Muraoka-Higashi 2-chome, Fujisawa, Kanagawa, \\ Japan
}

Corresponding author: Hiroki Nagase, Research Division, SCOHIA PHARMA, Inc., 26-1, Muraoka-Higashi 2-chome, Fujisawa, Kanagawa, Japan; hironse09@gmail.com

Received, October 12, 2020; Revised, November 20, 2020; Accepted, February 10, 2021; Published, February 17, 2021

\begin{abstract}
Purpose: We previously confirmed its anti-atherosclerotic effects by pre-treatment with compound-326, a selective delta-5 desaturase (D5D) inhibitor, in Western diet-fed ApoE knockout mice. In the present study, we evaluated effects of compound-326 in ApoE knockout mice with two different protocols for atherosclerosis development. Methods: In a post-treatment protocol, where the compound treatment started after 10 weeks pre-feeding of Western diet, compound-326 (1 and $3 \mathrm{mg} / \mathrm{kg} /$ day, p.o. for 12 weeks $)$ significantly reduced the atherosclerotic lesion area in the aorta $(24 \%$ reduction at $3 \mathrm{mg} / \mathrm{kg} / \mathrm{day})$. In another protocol using Paigen diet (containing 12.5\% cholesterol and 5\% sodium cholate), compound-326 (3 and $10 \mathrm{mg} / \mathrm{kg} / \mathrm{day}$, p.o. for 7 weeks) also significantly reduced the lesion area (36\% reduction at $3 \mathrm{mg} / \mathrm{kg} /$ day). Results: In both protocols, Compound-326 significantly reduced the hepatic ratio of arachidonic acid to dihomo- $\gamma$-linolenic acid, blood inflammatory eicosanoid production and plasma soluble intercellular adhesion molecule 1 (sICAM-1) levels, similarly to the previous pre-treatment study. Conclusions: Compound-326 exerted antiatherosclerotic effects in ApoE knockout mice with the two different protocols for atherosclerosis development further supporting D5D inhibition as a promising strategy in treating atherosclerosis.
\end{abstract}

\section{INTRODUCTION}

New drugs that can treat atherosclerosis and prevent subsequent cardiovascular events are urgently needed in clinical practice $(1,2)$. One of the important characteristics of atherosclerosis is chronic inflammation in the vascular wall (3). Recently, CANTOS trial revealed that canakinumab, an interleukin $1 \beta$ antibody, showed significantly lower rate of recurrent cardiovascular events independent of plasma lipid lowering (4). Antiinflammatory strategy for blood vessels is thus considered to be an effective measure for atherosclerotic plaque stabilization and rupture prevention $(5,6)$.

Delta-5 desaturase (D5D) is considered an attractive target molecule for treating atherosclerosis $(7,8)$. D5D is an enzyme mainly expressed in the liver $(9,10)$, which metabolizes dihomo- $\gamma$-linolenic acid (DGLA) into arachidonic acid (11). Arachidonic acid is considered to play a role in the progression of atherosclerosis because of its pro-inflammatory properties (12). Several reports have suggested that D5D gene polymorphism in humans is associated with coronary artery diseases $(13,14)$. D5D-deficient apolipoprotein E (ApoE) knockout mice were resistant to diet-induced development of atherosclerosis $(7,8)$. We recently discovered that an orally active and selective D5D inhibitor, compound-326, that exhibited in vitro D5D inhibition ( $\mathrm{IC}_{50}: 22 \mathrm{nM}$ ) in human cells (15), reduced liver and blood arachidonic acid levels in mice, accompanied by an increase in DGLA levels (8). In ApoE knockout mice fed a Western diet for 14 weeks, the atherosclerotic lesion area was significantly reduced by a 15 -week treatment with compound-326 (1-week pre-treatment plus 14-week concurrent treatment with Western diet). These results suggest that D5D inhibition could be a promising strategy for the treatment of atherosclerosis.

Diet composition and duration are known to affect the characteristics of atherosclerotic plaques (16). ApoE knockout mice fed a Western diet for a long duration showed an atherogenesis process strikingly similar to that seen in humans (17); Paigen diet (containing high cholesterol and cholate) induced severe dysfunction in the reverse cholesterol transport system (18), resulting in high plasma 
cholesterol levels and accelerated plaque development in ApoE knockout mice. These different diets are known to induce different pathologies and states of inflammation $(19,20)$. Since the inflammatory properties of atherosclerosis are known to vary in clinical practice according to stages of the pathology and to complications in patients (21-24), it is important to evaluate effects of D5D inhibition in several animal models of atherosclerosis with different states of inflammation and different pathophysiology.

In the present study, we investigated the antiatherosclerotic and anti-inflammatory effects of the D5D inhibitor compound-326 in ApoE knockout mice with two different protocols for atherosclerosis development.

\section{MATERIALS AND METHODS}

\section{Animals}

Male ApoE knockout mice (6 weeks old) were supplied by Takeda Rabics, Ltd (Fukuchiyama, Japan). All animals were maintained on a laboratory chow diet (CE-2, Clea Japan, Suita, Osaka) before experiments. Mice were allowed free access to water and food before and during experiments. The care and use of the animals and the experimental protocols used in this research were approved by the Experimental Animal Care and Use Committee of Takeda Pharmaceutical Co., Ltd., and were in accordance with the Guide to the Care and Use of Experimental Animal Care.

\section{Chemicals}

A D5D selective inhibitor, 2-(2,2,3,3,3pentafluoropropoxy)-3-[4-(2,2,2-trifluoroethoxy) phenyl]-5,7-dihydro-3H-pyrrolo[2,3-d]pyrimidine4,6-dione, compound-326 (15), was synthesized. Compound-326 was suspended in $0.5 \%(\mathrm{w} / \mathrm{v})$ methylcellulose (Wako, Osaka, Japan).

\section{Experimental design for atherosclerosis intervention studies: post-treatment protocol}

From 11 weeks of age, mice were fed a Western diet (D12079B, Research Diets, Inc., New Brunswick, NJ, USA) for 10 weeks to develop atherosclerotic lesions. Mice were then divided into four groups (n $=10-14$ ) based on body weight and plasma biochemical parameters (alanine aminotransferase [ALT], total cholesterol [TC], triglycerides [TG], and glucose [GLU]), and 10 mice were dissected to obtain data for this group (Pre group). Compound326 was administered to the rest of the mice at gravimetric doses of either 1 or $3 \mathrm{mg} / \mathrm{kg}$ of body weight per day for 12 weeks. The vehicle group received $0.5 \% \quad(\mathrm{w} / \mathrm{v})$ methylcellulose without compound-326. Food intake was measured every two weeks. Blood samples for interim measurements of plasma TC and the cell adhesion molecule sICAM-1 were obtained every four weeks from the orbital veins. After 12 weeks of treatment, mice were anesthetized by pentobarbital sodium (50-100 $\mathrm{mg} / \mathrm{kg}$, i.p.), and blood was collected from the abdominal aorta for eicosanoid analysis and from the caudal vena cava for other analyses. Whole aortas were dissected for quantification of atherosclerotic lesions and livers were dissected for fatty composition analysis and TG content measurement.

\section{Experimental design for atherosclerosis intervention studies: Paigen diet protocol}

From 13 weeks of age, mice were fed a control diet (D12337, Research Diets, Inc.) for one week and were divided into five groups $(n=6-12)$ based on body weight and plasma biochemical parameters (ALT, TC, TG, GLU). Compound-326 was administered at gravimetric doses of either $0.3,3$, or $10 \mathrm{mg} / \mathrm{kg}$ of body weight per day for 7 weeks. Control and vehicle groups received $0.5 \%(\mathrm{w} / \mathrm{v})$ methylcellulose without compound-326. In the latter 4 weeks, the mice were fed a Paigen diet (D12336, Research Diets, Inc., containing 12.5\% cholesterol and $5 \%$ sodium cholate) except for the control group, which received the control diet throughout the study period. Food intake was measured on week 1, 4, and 6 from the onset of the experiment three days. Blood samples for interim measurements of plasma TC and sICAM-1 were obtained from the orbital veins. After 7 weeks of treatment, mice were anesthetized by pentobarbital sodium $(50-100 \mathrm{mg} / \mathrm{kg}$, i.p. $)$, and blood was collected from the abdominal aorta for eicosanoid analysis and from the caudal vena cava for other analyses. Whole aortas were dissected for quantification of atherosclerotic lesions and the livers were dissected for fatty composition analysis and TG content measurement.

\section{Assessment of atherosclerotic lesions}

Aortas were carefully cleared of all connective tissues under a dissecting microscope and were cut open, washed with saline, and then fixed in $10 \%$ neutral buffered formalin for over 7 days. Aortas were stained with Oil Red $\mathrm{O}$ to detect the lipidaccumulated area. The stained areas were analyzed using Image-Pro Plus 6.0 (Media Cybernetics, Rockville, MD, USA) and expressed as a percentage of the surface area of the entire aorta. 


\section{Hepatic fatty acid composition analysis}

Liver samples were homogenized in 4-fold liver wet weight of saline. The homogenized liver samples were added to a 4.5-fold amount of hexaneisopropanol-butylated hydroxytoluene (60:40:0.01, $\mathrm{v} / \mathrm{v} / \mathrm{w})$ containing $800 \mu \mathrm{M}$ margaric acid as an internal standard, and were vortexed for $30 \mathrm{~min}$. The hexane phase was removed to a plastic tube and evaporated to dryness under a nitrogen stream and vacuum. The phospholipid fraction was isolated from the residue using Sep-Pak PSA columns (Waters, Milford, MA, USA), based on previously described procedures (25), and was derivatized using a YMC long- and short-chain fatty acid labeling kit (YMC, Kyoto, Japan). Samples were redissolved in methanol and were analyzed by reverse-phase HPLC using an LC column $(6.0 \varphi \times 250 \mathrm{~mm}$, Shim-pack XR-ODS, Shimadzu, Kyoto, Japan) and by UV absorbance detection at $230 \mathrm{~nm}$. HPLC solvent conditions were as follows: A mobile phase of acetonitrile-water-trifluoro acetic acid $(1,660: 340: 0.004, \mathrm{v} / \mathrm{v} / \mathrm{w})$, a flow rate of $1.4 \mathrm{~mL} / \mathrm{min}$, and a temperature of $40^{\circ} \mathrm{C}$.

\section{Measurement of hepatic TG contents}

Homogenized liver samples were added to an equal amount of $0.4 \% \mathrm{CaCl}_{2}(\mathrm{w} / \mathrm{v})$ solution and a 4.5 -fold amount of hexane-isopropanol-butylated hydroxytoluene (60:40:0.01, v/v/w), and were vortexed for $30 \mathrm{~min}$. The hexane phase was removed to a plastic tube and evaporated to dryness under a nitrogen stream and vacuum. The residues were suspended in nonaethylene glycol monododecyl ether-1,4-dioxane $(1: 1, \mathrm{v} / \mathrm{v})$. TG contents were determined using a Triglyceride E-test (Wako).

\section{Measurements of plasma ALT, TC, sICAM-1, and MCP-1}

Blood samples were centrifuged $(20,000 \times \mathrm{g})$ at $4{ }^{\circ} \mathrm{C}$ for five min to isolate plasma and were 6-fold, 200fold, and 2-fold diluted with saline for quantification of TC, sICAM-1, and monocyte chemoattractant protein 1 (MCP-1), respectively. ALT and TC levels were determined using a 9000 Series Automatic Analyzer (Hitachi, Tokyo, Japan). sICAM and MCP1 were assessed by a Mouse Soluble ICAM-1 (CD54) ELISA kit (EMICAM1, Thermo Fisher Scientific, Yokohama, Japan) and a Quantikine Mouse CCL2/JE/MCP-1 kit (MJE00, R\&D Systems, Inc., Minneapolis, MN, USA), respectively.

\section{Blood eicosanoid production assay}

Blood eicosanoid production assay was performed as described previously (8). Blood samples were stimulated with $30 \mu \mathrm{M}$ A23187 and $10 \mu \mathrm{M}$ fMLP (NFormylmethionyl-leucyl-phenylalanine) and were incubated at $37^{\circ} \mathrm{C}$ for $10 \mathrm{~min}$. Samples were centrifuged $(20,000 \times \mathrm{g})$ at room temperature for 5 min to isolate plasma. Blood eicosanoid composition was analyzed by LC/MS/MS.

\section{STATISTICAL ANALYSIS}

Results are expressed as the mean \pm SEM. Statistical significance between two groups was determined by Student's $t$-test (for homogenous data) or Welch's test (for non-homogenous data). Statistical significance between groups of multiple doses of test compounds was determined by a two-tailed Williams' test (for homogenous data) or a two-tailed Shirley-Williams test (for non-homogenous data). Differences were considered significant at $p<0.05$.

\section{RESULTS}

\section{Post-treatment protocol \\ Anti-atherosclerotic effects of compound-326}

To evaluate the effects of D5D inhibition on atherogenic progression in a post-treatment protocol, atherosclerotic lesions were developed in advance by a 10-week administration of a Western diet to ApoE knockout mice (Pre group). The group developed a $14 \%$ surface lesion area for the entire aorta, indicating sufficient formation of the atherosclerotic lesion area before the administration of compound326. The vehicle group developed a $38 \%$ atherosclerotic lesion area over additional 12 weeks of the Western diet, indicating continuous atherogenic progression during the drug treatment phase. A 12-week post-treatment with compound$326(1-3 \mathrm{mg} / \mathrm{kg} / \mathrm{day}, \quad$ p.o. $)$ reduced the atherosclerotic lesion area of the aorta in a dosedependent manner (16 and $24 \%$ reduction at 1 and 3 $\mathrm{mg} / \mathrm{kg} /$ day, Figure 1), statistically significant at 3 $\mathrm{mg} / \mathrm{kg} /$ day. The lesion area reduction was $38 \%$ at 3 $\mathrm{mg} / \mathrm{kg}$ when the Pre group was set as the basal line, so the efficacy of compound-326 was comparable to that seen previously in the previous pre-treatment study (8).

In addition, Smirnov-Grubbs' outlier test revealed that the ones with the largest lesion areas in vehicle, $1 \mathrm{mg} / \mathrm{kg}$ and $3 \mathrm{mg} / \mathrm{kg}$ groups were outliers $(p<0.05)$. When excluded these three outliers, twotailed Williams' test indicated the statistically significant reduction of the lesion area in the 1 and 3 

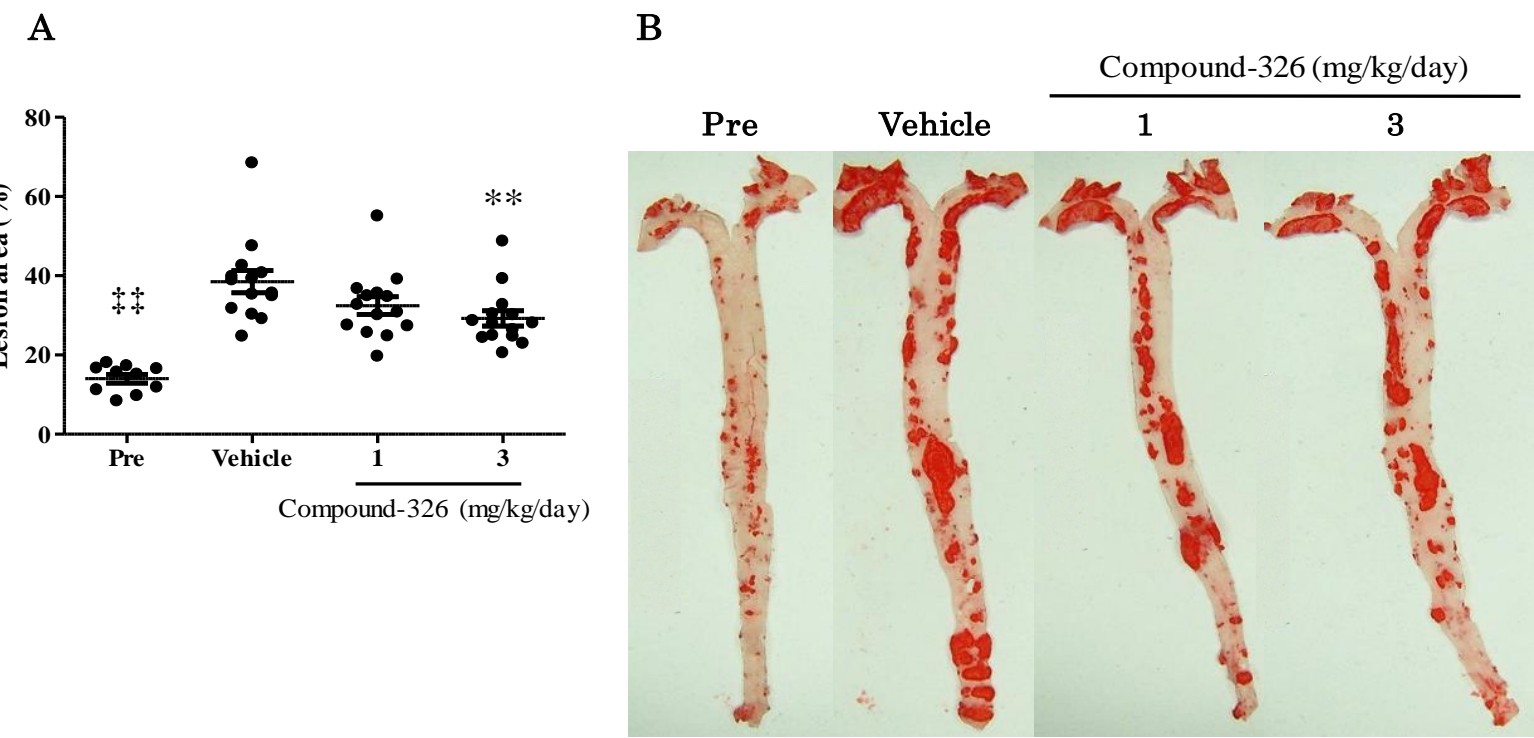

Figure 1. Effects of compound-326 on atherosclerotic lesion area in ApoE knockout mice with the post-treatment protocol. Percentage of surface lesion area over the entire aorta were assessed by Oil Red O staining. From 11 weeks of age, mice were fed a Western diet for 10 weeks to develop atherosclerotic lesions. Ten mice were dissected at this point to obtain data for Pre group. Compound-326 was administered to the rest of the mice at gravimetric doses of either $1 \mathrm{or} 3 \mathrm{mg} / \mathrm{kg}$ of body weight per day. Vehicle group received $0.5 \%(\mathrm{w} / \mathrm{v}) \mathrm{MC}$ without compound-326. After 12 weeks of administration, whole aortas were dissected for quantification of atherosclerotic lesions. (A) Percentage of surface lesion area for the entire aorta. (B) Representative images of oil red-O staining of en-face preparations of aortas in each group. Results are expressed as mean \pm SEM (Pre: $\mathrm{n}=10$, others: $\mathrm{n}=14$ ). ${ }^{\sharp} p<0.01$ vs. vehicle (Welch's test). ${ }^{* *} p<0.01$ vs. vehicle (Williams' test).

$\mathrm{mg} / \mathrm{kg}$ groups $(p<0.01)$. This analysis suggest that the outliers of the data may affect the statistics.

\section{Effects of compound-326 on fatty acid composition and blood eicosanoid production}

To confirm the mechanism of action of compound326, hepatic fatty acid composition and blood eicosanoid production (stimulated by calcium ionophore A23187 and fMLP) were measured at the end of the treatment period. Compound-326 significantly reduced the reaction product, arachidonic acid contents $(33 \%$ and $28 \%$ reduction at 1 and $3 \mathrm{mg} / \mathrm{kg} /$ day, respectively; Figure 2A), and increased the substrate, DGLA contents $(163 \%$ and $284 \%$ increase at 1 and $3 \mathrm{mg} / \mathrm{kg} /$ day, respectively; Figure 2B) in the liver in a dose-dependent manner. Compound-326 therefore significantly reduced the arachidonic acid/DGLA ratio in the liver $(74 \%$ and $81 \%$ reduction at 1 and $3 \mathrm{mg} / \mathrm{kg} /$ day, respectively: Figure 2C). Similar changes in fatty acid composition were also observed in the blood (data not shown). Corresponding to the composition change in hepatic fatty acids, blood eicosanoid production, a biomarker for D5D inhibitors, was also altered. Arachidonic acid-derived eicosanoids $\mathrm{PGE}_{2}$ ( $41 \%$ and $43 \%$ reduction at 1 and $3 \mathrm{mg} / \mathrm{kg} /$ day, respectively; Figure 2D) and $\mathrm{TXB}_{2}(43 \%$ and $37 \%$ reduction at 1 and $3 \mathrm{mg} / \mathrm{kg} /$ day, respectively; Figure 2E) were significantly reduced. Production of $\mathrm{LTB}_{4}$, an arachidonic acid-derived eicosanoid, in blood was not altered (Figure 2F). A DGLA-derived eicosanoid, 15-HETrE, increased significantly following compound-326 administration (321\% and 636\% increase at 1 and $3 \mathrm{mg} / \mathrm{kg} /$ day, respectively: Figure $2 \mathrm{G})$.

Effects of compound-326 on inflammatory markers Compound-326 suppressed plasma sICAM-1 levels during treatment (Figure 3A), resulting in a significant reduction in area under the curve (AUC) ( $8.4 \%$ reduction at $3 \mathrm{mg} / \mathrm{kg} /$ day; Figure $3 \mathrm{~B})$. In addition, compound-326 did not alter plasma cholesterol levels (Table 1), suggesting that the antiatherosclerotic effects were independent of plasma cholesterol levels and were due to anti-inflammatory effects. 

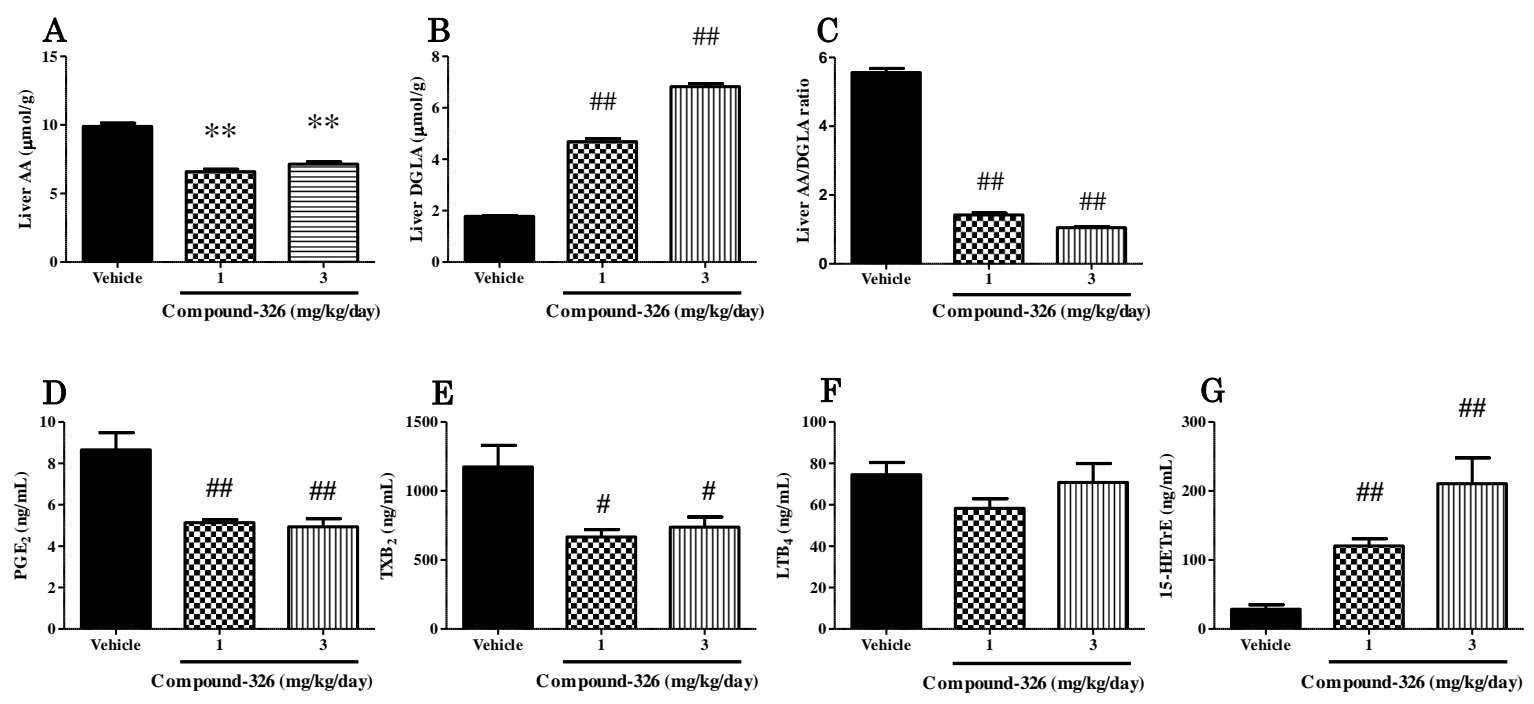

Figure 2. Effects of compound-326 on hepatic fatty acid composition (A-C) and blood eicosanoid production (D-G) in ApoE knockout mice with the post-treatment protocol. Livers and bloods were obtained from animals shown in Figure 1 at the end of the study. (A) Arachidonic acid (AA) contents. (B) Dihomo- $\gamma$-linolenic acid (DGLA) contents. (C) $\mathrm{AA} / \mathrm{DGLA}$ ratio. Results are expressed as mean $\pm \mathrm{SEM}(\mathrm{n}=14)$. (D) $\mathrm{PGE}_{2}$, an arachidonic acid (AA) derivative. (E) $\mathrm{TXB}_{2}$, an AA derivative. (F) LTB 4 , an AA derivative. (G) 15-HETrE, a dihomo- $\gamma$-linolenic acid (DGLA) derivative. Results are expressed as mean \pm SEM $(\mathrm{n}=7) .{ }^{* *} p<0.01$ vs. vehicle (Williams' test). ${ }^{\#} p<0.05,{ }^{\# \#} p<0.01$ vs. vehicle (Shirley-Williams test).

Table 1. Effects of compound-326 on plasma total cholesterol (mg/dL) in the post-treatment protocol.

\begin{tabular}{lcccc}
\hline & \multicolumn{4}{c}{ Weeks after commencing of compound-326 treatment } \\
\cline { 2 - 5 } Group & $\mathbf{0}$ & $\mathbf{4}$ & $\mathbf{8}$ & $\mathbf{1 2}$ \\
\hline Vehicle & $1,459 \pm 65$ & $1,451 \pm 70$ & $1,349 \pm 98$ & $1,313 \pm 67$ \\
$\mathbf{1} \mathbf{~ m g} / \mathbf{k g} /$ day & $1,494 \pm 55$ & $1,456 \pm 59$ & $1,490 \pm 51$ & $1,288 \pm 56$ \\
$\mathbf{3} \mathbf{~ m g} / \mathbf{k g} /$ day & $1,500 \pm 53$ & $1,406 \pm 54$ & $1,392 \pm 52$ & $1,298 \pm 38$ \\
\hline
\end{tabular}

Results are expressed as mean $\pm \operatorname{SEM}(n=14)$.

A

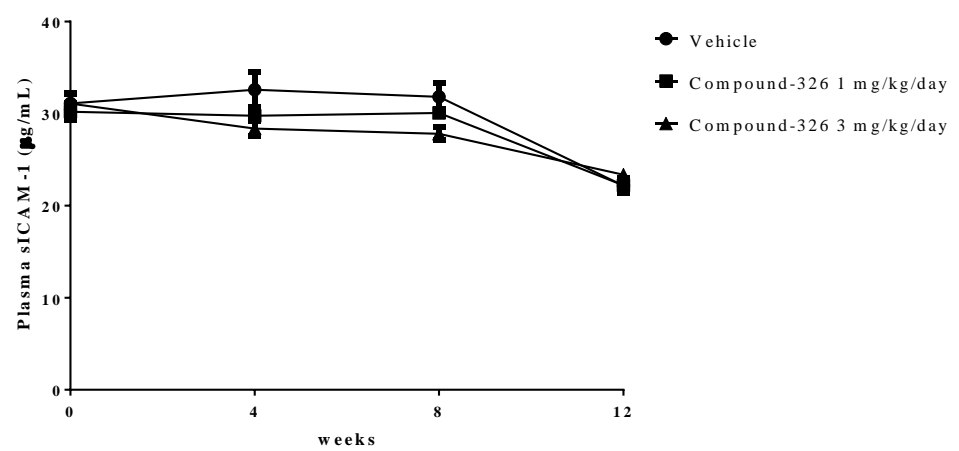

B

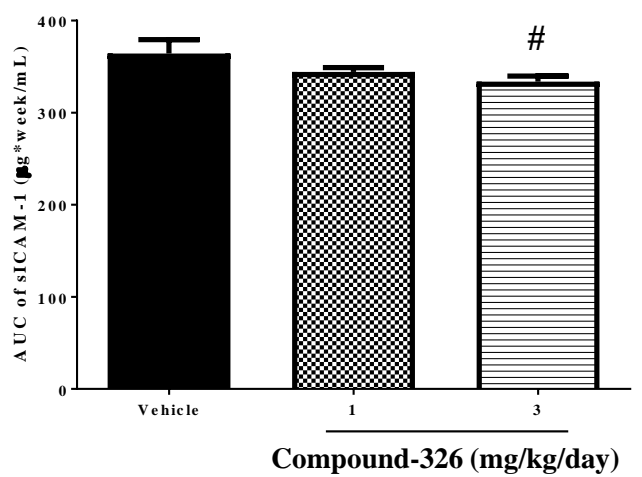

Figure 3. Effects of compound-326 on plasma sICAM-1 levels in ApoE knockout mice with the post-treatment protocol. Plasma samples were collected every four weeks from the onset of administration from animals shown in Figure 1. (A) Time-dependent alteration of plasma sICAM-1 levels. (B) Area under the curve (AUC) of plasma sICAM-1 concentrations. Plasma sICAM-1 levels were measured at baseline and on weeks 4, 8, and 12. Results are expressed as mean $\pm \operatorname{SEM}(\mathrm{n}=14) .{ }^{\#} p<0.05$ vs. vehicle (Shirley-Williams test). 


\section{Other findings related to compound-326 administration}

Compound-326 suppressed Western diet-induced body weight gain (Figure 4). Food intake was not altered (Vehicle: $2.81 \pm 0.14 \mathrm{~g} / \mathrm{day}, 1 \mathrm{mg} / \mathrm{kg} /$ day: $2.92 \pm 0.18 \mathrm{~g} / \mathrm{day}, 3 \mathrm{mg} / \mathrm{kg} /$ day: $2.82 \pm 0.10 \mathrm{~g} /$ day, mean \pm SEM, $n=14$ ), indicating that the suppression of body weight gain by compound-326 was independent of food intake.

Liver weight (Vehicle: $1.88 \pm 0.14 \mathrm{~g}, 1 \mathrm{mg} / \mathrm{kg}$ /day: $1.87 \pm 0.07 \mathrm{~g}, 3 \mathrm{mg} / \mathrm{kg} /$ day: $1.67 \pm 0.06 \mathrm{~g} /$ day) and hepatic TG (Vehicle: $137 \pm 24 \mu \mathrm{g} / \mathrm{mg}$ liver, 1 $\mathrm{mg} / \mathrm{kg} /$ day: $136 \pm 12 \mu \mathrm{g} / \mathrm{mg}$ liver, $3 \mathrm{mg} / \mathrm{kg} /$ day: $89 \pm$ $8.3 \mu \mathrm{g} / \mathrm{mg}$ liver) were not altered by compound-326 (mean \pm SEM, $n=14)$. Plasma ALT were not altered (Vehicle: $80.3 \pm 30.5 \mathrm{U} / \mathrm{L}, 1 \mathrm{mg} / \mathrm{kg} /$ day: $51.0 \pm 5.36$ $\mathrm{U} / \mathrm{L}, 3 \mathrm{mg} / \mathrm{kg} /$ day: $31.3 \pm 3.22 \mathrm{U} / \mathrm{L}$, mean $\pm \mathrm{SEM}$, $\mathrm{n}=14$ ) by compound-326.

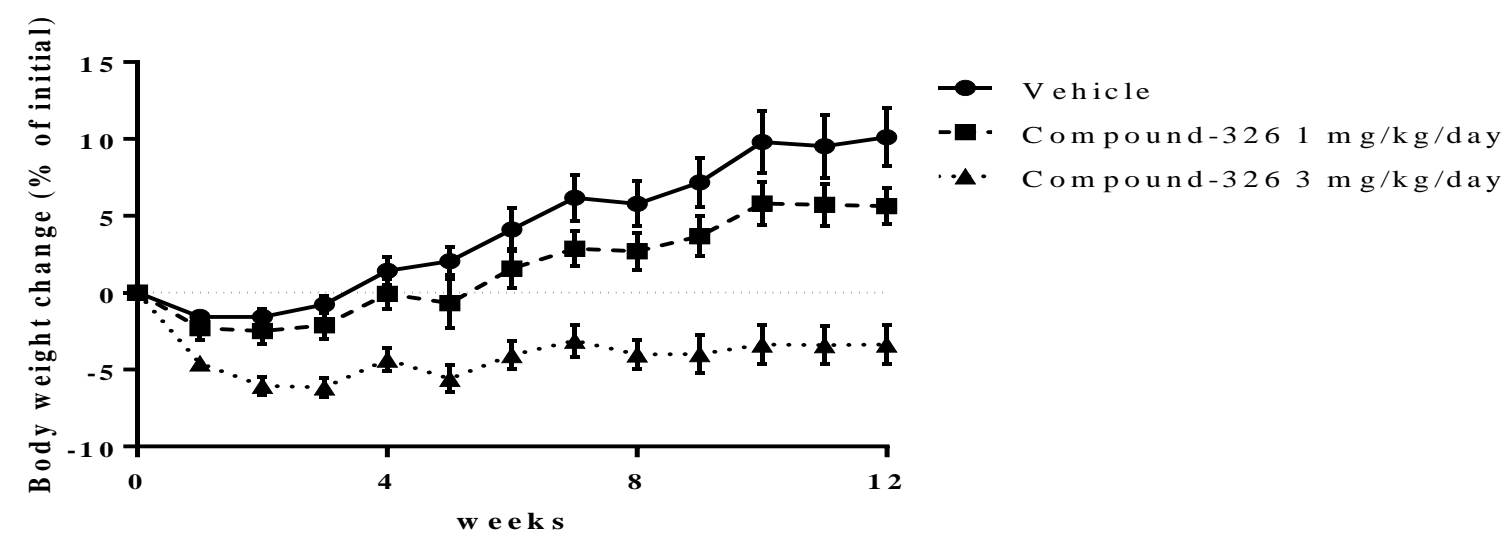

Figure 4. Effects of compound-326 on body weight changes in ApoE knockout mice with the post-treatment protocol. Results are expressed as mean \pm SEM $(n=14)$.

\section{Paigen diet protocol}

Anti-atherosclerotic effects of compound-326

To evaluate the effects of D5D inhibition on atherogenic progression induced by Paigen diet (containing $12.5 \%$ cholesterol and 5\% sodium cholate), the atherosclerotic lesion area in the aorta was determined after 7 weeks of compound-326 administration (0.3-10 mg/kg/day, p.o., with a 3week pre-treatment before commencing the Paigen diet). Compound-326 significantly reduced the atherosclerotic lesion area of the aorta in a dosedependent manner (36\% and $38 \%$ reduction at 3 and $10 \mathrm{mg} / \mathrm{kg} /$ day, respectively: Figure 5).

\section{Effects of compound-326 on fatty acid composition and blood eicosanoid production}

Hepatic fatty acid composition and blood eicosanoid production (stimulated by calcium ionophore A23187 and fMLP) were measured at the end of the treatment period. Compound-326 significantly reduced the product arachidonic acid contents $(36 \%$ and $56 \%$ reduction at 3 and $10 \mathrm{mg} / \mathrm{kg} /$ day, respectively; Figure 6A) and increased the substrate DGLA contents $(56 \%, 347 \%$, and $676 \%$ increase at
$0.3,3$, and $10 \mathrm{mg} / \mathrm{kg} /$ day, respectively; Figure $6 \mathrm{~B}$ ) in the liver in a dose-dependent manner. Compound326 therefore significantly reduced the arachidonic acid/DGLA ratio in the liver $(39 \%, 84 \%$, and $94 \%$ reduction at $0.3,3$, and $10 \mathrm{mg} / \mathrm{kg} /$ day, respectively: Figure 6C), in a dose-dependent manner. Similar changes in fatty acid composition were also observed in the blood (data not shown). Corresponding to the composition change in hepatic fatty acids, blood eicosanoid production was also altered. Arachidonic acid-derived eicosanoids $\mathrm{PGE}_{2} \quad(56 \%$ and $87 \%$ reduction at 3 and $10 \mathrm{mg} / \mathrm{kg} /$ day, respectively; Figure $6 \mathrm{D}), \mathrm{TXB}_{2}(46 \%$ and $82 \%$ reduction at 3 and $10 \mathrm{mg} / \mathrm{kg} /$ day, respectively; Figure $6 \mathrm{E}$ ), and $\mathrm{LTB}_{4}$ $(53 \%$ and $83 \%$ reduction at 3 and $10 \mathrm{mg} / \mathrm{kg} / \mathrm{day}$, respectively; Figure $6 \mathrm{~F}$ ) were significantly reduced. The DGLA-derived eicosanoid 15-HETrE increased significantly $(104 \%, 626 \%$, and $754 \%$ increase at 0.3 , 3 , and $10 \mathrm{mg} / \mathrm{kg} /$ day, respectively: Figure $6 \mathrm{G}$ ) following compound-326 administration.

\section{Effects of compound-326 on inflammatory markers}

Compound-326 suppressed plasma sICAM-1 levels 
during treatment (Figure 7A), resulting in a significant reduction in area under the curve (AUC) $(11 \%$ reduction at $10 \mathrm{mg} / \mathrm{kg} /$ day; Figure $7 \mathrm{~B})$. Compound-326 also significantly reduced plasma MCP-1 levels (30\% reduction at $10 \mathrm{mg} / \mathrm{kg} /$ day;
Figure 7C) in a dose-dependent manner. In addition, compound-326 did not alter plasma TC levels (Table 2 ), suggesting that the anti-atherosclerotic effects were independent of plasma cholesterol levels and were due to anti-inflammatory effects.
A

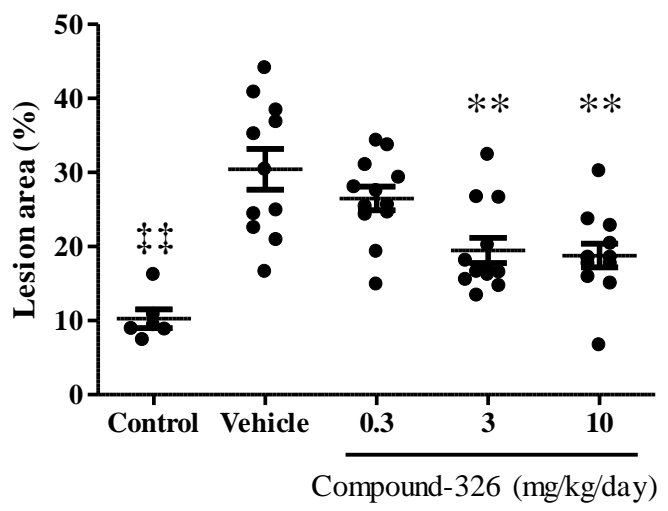

B

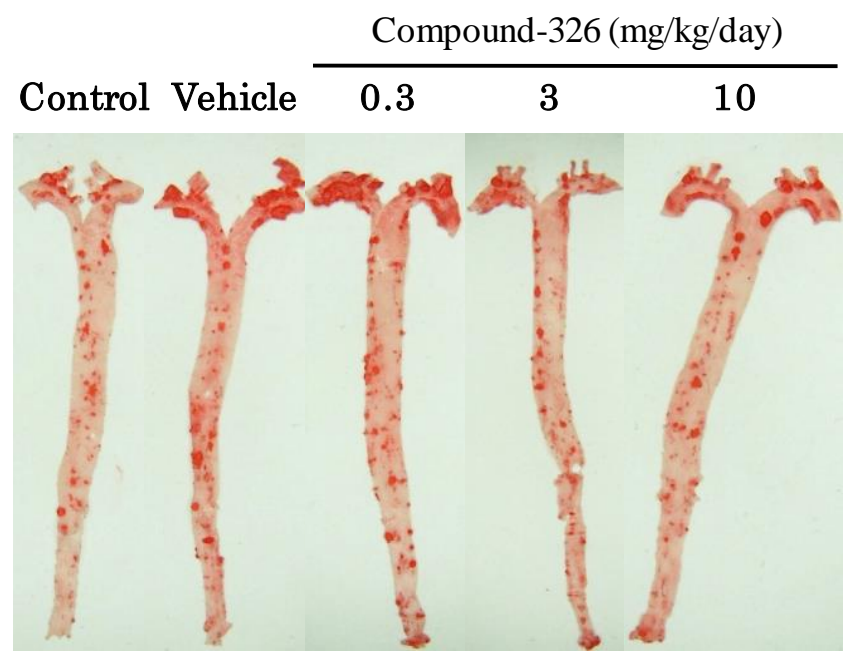

Figure 5. Effects of compound-326 on atherosclerotic lesion area in ApoE knockout mice with the Paigen diet protocol. From 13 weeks of age, mice were fed a control diet for one week and were divided into five groups (control: $n=6$, others: $\mathrm{n}=12$ ). Compound-326 was administered at gravimetric doses of either $0.3,3$, or $10 \mathrm{mg} / \mathrm{kg}$ of body weight per day for 7 weeks. Control and vehicle groups received $0.5 \%$ (w/v) methylcellulose without compound-326. In the latter 4 weeks, the mice were fed a Paigen diet except for the control group, which received the control diet throughout the study period. After 7 weeks of administration, whole aortas were dissected for quantification of atherosclerotic lesions. (A) Percentage of surface lesion area for the entire aorta. (B) Representative images of oil red-O staining of en-face preparations of aortas in each group. Results are expressed as mean \pm SEM (control: $\mathrm{n}=6$, others: $\mathrm{n}=12$ ). ${ }^{\star} p<0.01$ vs. vehicle (Welch's test). ${ }^{* *} p<0.01$ vs. vehicle (Williams' test).
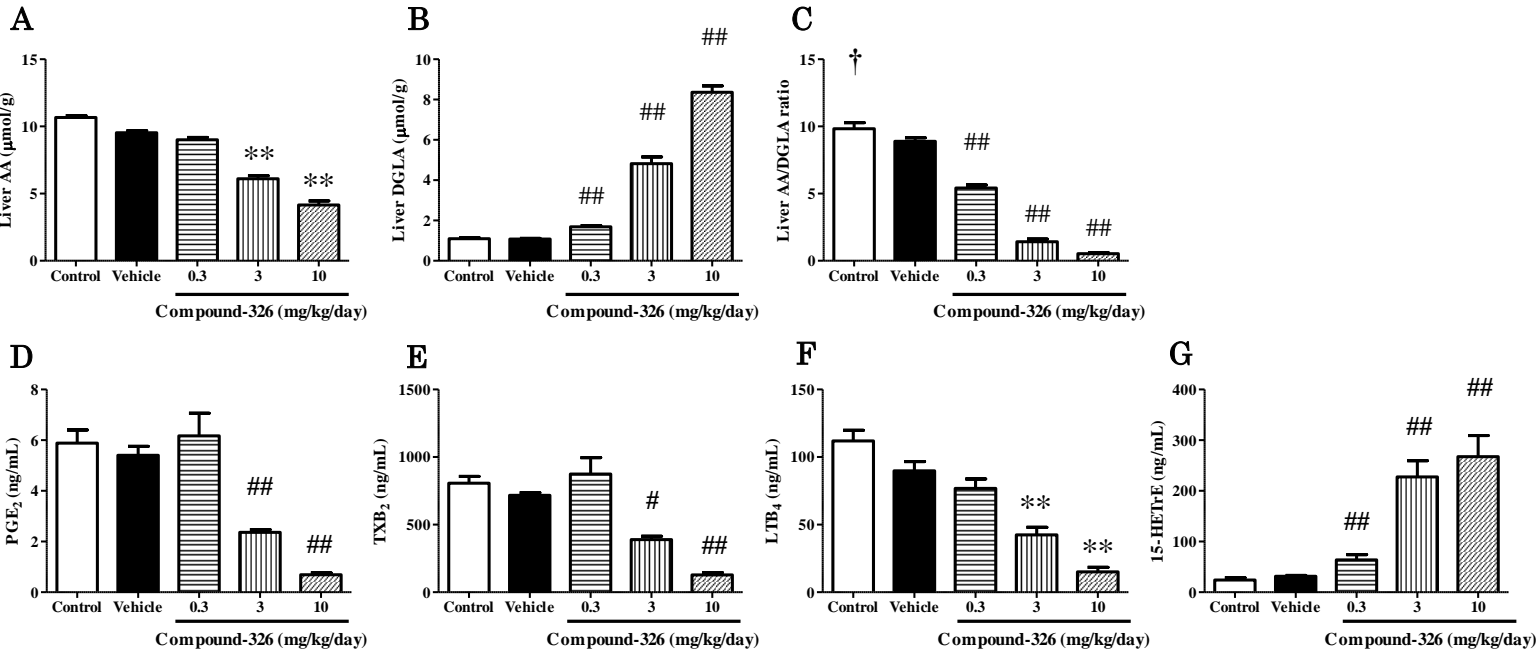

Figure 6. Effects of compound-326 on hepatic fatty acid composition (A-C) and blood eicosanoid production (D-G) in ApoE knockout mice with the Paigen diet protocol. Livers and bloods were obtained from animals shown in Figure 5 at the end of the study. (A) arachidonic acid (AA) contents. (B) dihomo- $\gamma$-linolenic acid (DGLA) contents. (C) AA/DGLA ratio. Results are expressed as mean \pm SEM (control: $n=6$, others: $n=12$ ). (D) Prostaglandin E2 $\left(P_{G E}\right.$ ), an arachidonic 
acid (AA) derivative. (E) $\mathrm{TXB}_{2}$, an AA derivative. (F) LTB 4 , an AA derivative. (G) 15-HETrE, a dihomo- $\gamma$-linolenic acid (DGLA) derivative. ${ }^{\dagger} p<0.05$ vs. vehicle ( $t$-test). ${ }^{* *} p<0.01$ vs. vehicle (Williams’ test). ${ }^{\#} p<0.05$, ${ }^{\#} p<0.01$ vs. vehicle (Shirley-Williams test).

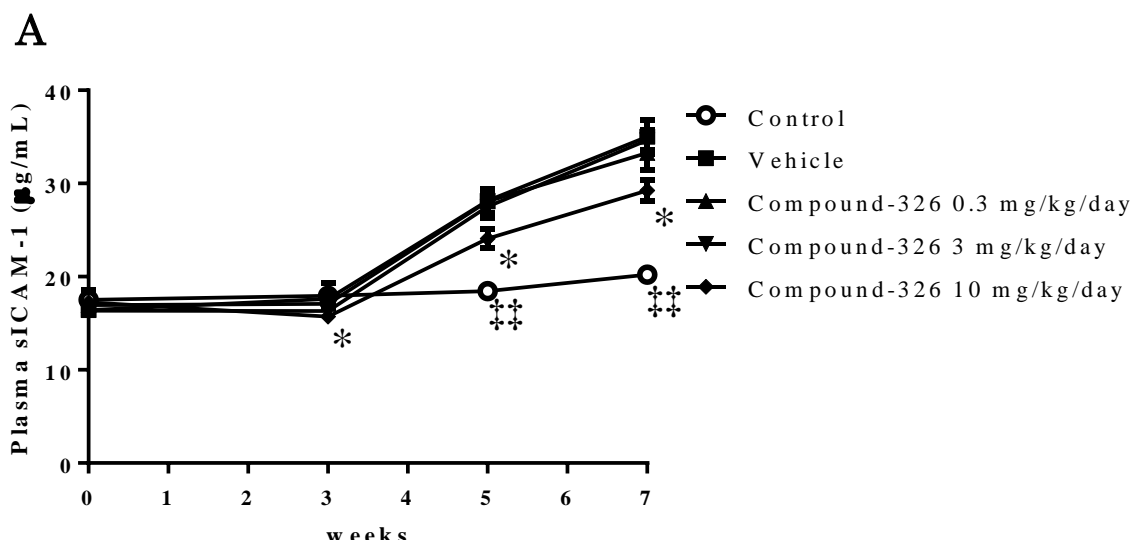

B

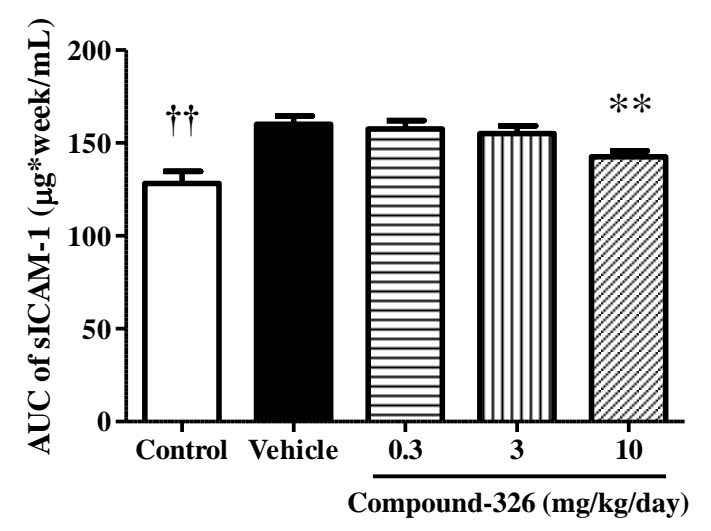

C

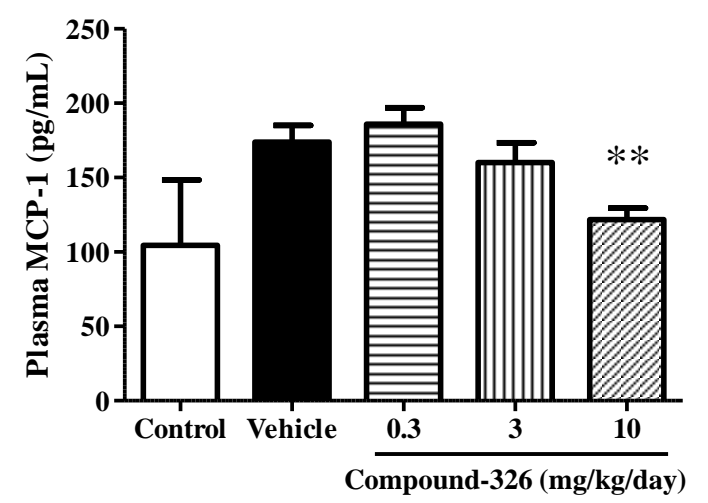

Figure 7. Effects of compound-326 on inflammatory markers in ApoE knockout mice with the Paigen diet protocol. Plasma samples were collected on weeks 3, 5, 7 from the onset of administration from animals shown in Figure 5. (A) Time-dependent alteration of plasma sICAM-1 levels. (B) Area under the curve (AUC) of plasma sICAM-1 concentrations. Plasma sICAM-1 levels were measured at baseline and on weeks 3, 5, and 7. (C) Plasma monocyte chemoattractant protein (MCP)-1 concentrations after 7 weeks of treatment. Results are expressed as mean \pm SEM (control: $\mathrm{n}=6$, others: $\mathrm{n}=12) .{ }^{\dagger} p<0.01$ vs. vehicle $\left(t\right.$-test). ${ }^{* *} p<0.01$ vs. vehicle (Williams' test).

Table 2. Effects of compound-326 on plasma total cholesterol (mg/dL) in the Paigen diet protocol.

\begin{tabular}{lcccc}
\hline & \multicolumn{4}{c}{ Weeks after commencing of compound-326 treatment } \\
\cline { 2 - 5 } Group & $\mathbf{0}$ & $\mathbf{3}$ & $\mathbf{5}$ & $\mathbf{7}$ \\
Control & $783 \pm 58$ & $803 \pm 84$ & $873 \pm 88$ & $938 \pm 89^{\dagger \dagger}$ \\
Vehicle & $787 \pm 30$ & $826 \pm 34$ & $4,022 \pm 131$ & $4,162 \pm 112$ \\
$\mathbf{0 . 3} \mathbf{~ m g / k g / d a y}$ & $798 \pm 40$ & $820 \pm 32$ & $4,275 \pm 112$ & $4,219 \pm 123$ \\
$\mathbf{3 ~} \mathbf{~ m g / k g / d a y}$ & $790 \pm 32$ & $856 \pm 40$ & $4,297 \pm 142$ & $4,260 \pm 141$ \\
$\mathbf{1 0 ~} \mathbf{~ m g / k g / d a y}$ & $795 \pm 31$ & $801 \pm 29$ & $4,271 \pm 177$ & $4,084 \pm 237$ \\
\hline
\end{tabular}

Results are expressed as mean \pm SEM (control: $\mathrm{n}=6$, others: $\mathrm{n}=12) .{ }^{\dagger} p<0.01$ vs. vehicle $(t$-test).

Other findings related to compound-326 administration

Compound-326 enhanced Paigen diet-induced body weight reduction (Figure $8 \mathrm{~A})$. Food intake was not altered (Vehicle: $2.88 \pm 0.12 \mathrm{~g} /$ day, $0.3 \mathrm{mg} / \mathrm{kg} /$ day: $2.83 \pm 0.13 \mathrm{~g} /$ day, $3 \mathrm{mg} / \mathrm{kg} /$ day: $2.87 \pm 0.11 \mathrm{~g} /$ day, 10 
$\mathrm{mg} / \mathrm{kg} /$ day: $2.83 \pm 0.14 \mathrm{~g} /$ day, mean $\pm \mathrm{SEM}, \mathrm{n}=12$ ), suggesting that the suppression of body weight by compound-326 was not caused by the reduction of food intake. Compound-326 significantly increased liver weight and hepatic TG contents in a dose- dependent manner (Figure 8B,8C). Plasma ALT were not altered (Vehicle: $75.8 \pm 13.3 \mathrm{U} / \mathrm{L}, 0.3$ $\mathrm{mg} / \mathrm{kg} /$ day: $53.5 \pm 6.00 \mathrm{U} / \mathrm{L}, 3 \mathrm{mg} / \mathrm{kg} /$ day: $114 \pm 46.1$ $\mathrm{U} / \mathrm{L}, 10 \mathrm{mg} / \mathrm{kg} /$ day: $54.7 \pm 3.88 \mathrm{U} / \mathrm{L}$, mean \pm SEM, $\mathrm{n}$ $=12$ ) by compound-326.

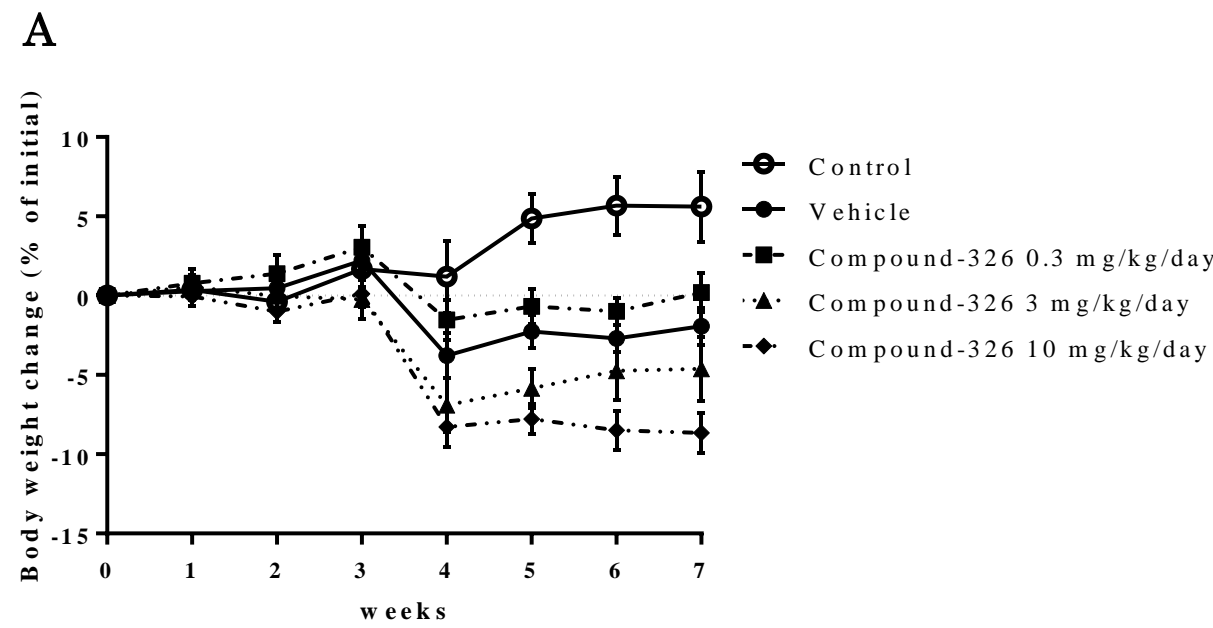

B

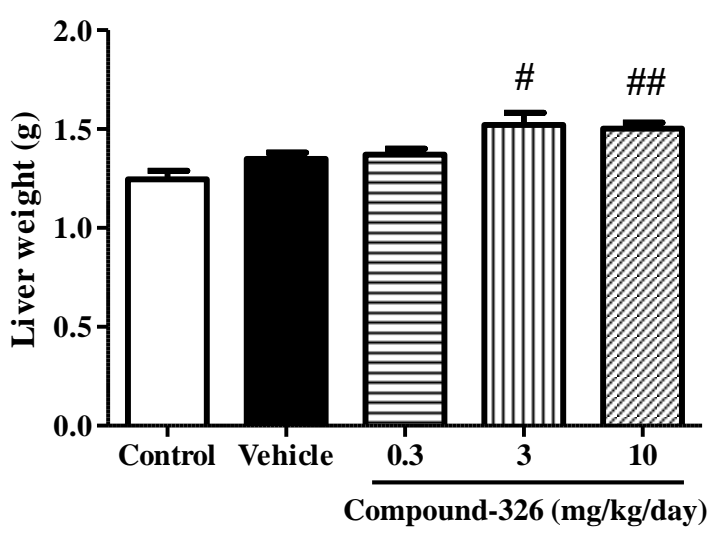

C

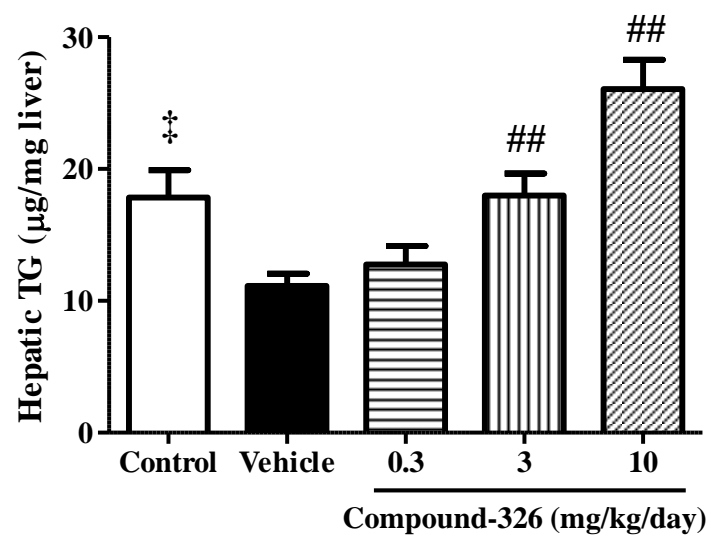

Figure 8. Effects of compound-326 on body weight changes (A), liver weight (B) and hepatic triglyceride (TG) contents (C) in ApoE knockout mice with the Paigen diet protocol. (A) Body weight change. Results are expressed as mean \pm SEM (control: $n=6$, others: $n=12$ ). (B) Liver weight. (C) Hepatic TG contents. Results are expressed as mean \pm SEM (control: $\mathrm{n}=6$, others: $\mathrm{n}=12$ ). ${ }^{\star} p<0.05$ vs. vehicle (Welch's test). ${ }^{\#} p<0.05,{ }^{\#} p<0.01$ vs. vehicle (Shirley-Williams test).

\section{DISCUSSION}

In the present study, we demonstrated that a D5D inhibitor, compound-326, exerts anti-atherosclerotic effects in ApoE knockout mice with two different protocols for atherosclerosis development. The main findings in this study were as follows: 1) Compound326 exhibited anti-atherosclerotic effects in a dosedependent manner with similar effective dose ranges in the two protocols with different states of inflammation; 2) compound-326 decreased hepatic arachidonic acid levels and increased hepatic DGLA levels in both protocols; 3) compound-326 decreased blood production of arachidonic acid-derived eicosanoids and increased blood production of a DGLA-derived eicosanoid in both protocols; 4) compound-326 reduced plasma sICAM-1 levels without altering plasma cholesterol levels in both protocols; 5) compound-326 exhibited suppressive effects on body weight gain in both protocols; 6) compound-326 increased hepatic TG in ApoE knockout mice fed Paigen diet.

This D5D inhibitor exerted antiatherosclerotic effects in a dose-dependent manner in ApoE knockout mice with both protocols. The effective dose ranges in both protocols were similar 
to those reported in previous pre-treatment study (8). In the vehicle-treated groups of this study, Western diet induced a $38.5 \%$ atherosclerotic lesion area and a stable sICAM-1 level of approximately $30 \mu \mathrm{g} / \mathrm{mL}$ at 10-22 weeks, while Paigen diet developed a $30.5 \%$ atherosclerotic lesion area and a $35 \mu \mathrm{g} / \mathrm{mL}$ sICAM-1 level at 4 weeks. This suggests a clear difference in the relationship between atherosclerotic lesion formation and inflammatory status in these two protocols. Several reports have also indicated that the two diets display different inflammation states. The Paigen diet triggered greater MCP-1 and interleukin 6 gene expression in the mouse aorta compared to that reported with a Western diet. Mice fed the two diets exhibit different expression patterns of M1 and M2 macrophages, suggesting that the macrophages that accumulate in atherosclerotic lesions vary in polarity. Several other genes are differentially expressed in the two models (17), suggesting a difference in atherogenic progression. Paigen diet-fed mice have been reported not to develop lesions beyond the early foam cells and fatty streaks, while Western diet-fed mice form monocytic adhesions and advanced lesions at earlier stages, displaying a histological similarity to tissues from humans (19). The Paigen diet itself is inflammatory because of its cholic acid levels, leading to liver toxicity by inducing hepatic NF- $\mathrm{BB}$ activation, which is not seen in Western diet-fed mice (19). These reports outline the differences between the two diet-induced atherosclerosis, supporting the importance of testing drug efficacy in different protocols for atherosclerosis development.

D5D inhibition by compound-326 was confirmed in both protocols by a decrease in liver levels of arachidonic acid and an increase in DGLA, a consistent fatty acid compositional alteration in blood, reduced blood production of arachidonic acidderived inflammatory eicosanoids such as $\mathrm{PGE}_{2}$, $\mathrm{TXB}_{2}$, and $\mathrm{LTB}_{4}$, and increased blood production of DGLA-derived anti-inflammatory eicosanoids such as 15-HETrE. However, the decrease in hepatic arachidonic acid and the reduction in blood production of arachidonic acid-derived inflammatory eicosanoids did not show a clear dosedependency in the post-treatment protocol, displaying a maximum effect on arachidonic acid reduction at a dose of $1 \mathrm{mg} / \mathrm{kg} /$ day. In contrast, the increase in hepatic DGLA and blood production of DGLA-derived anti-inflammatory eicosanoids showed a clear dose-dependency. Since a 3$\mathrm{mg} / \mathrm{kg} /$ day compound-326 treatment showed more potent anti-atherosclerotic effects than the 1$\mathrm{mg} / \mathrm{kg} /$ day dose did, these results may suggest the importance of DGLA elevation and DGLA-derived anti-inflammatory eicosanoid increase for D5D inhibition in showing anti-atherosclerotic effects. Several studies have indicated the involvement of eicosanoids in inflammation and atherosclerosis. Studies on mice lacking EP2 and EP4, receptors for $\mathrm{PGE}_{2}$, described pro-inflammatory and proatherogenic properties of $\mathrm{PGE}_{2}$ (26). $\mathrm{TXA}_{2}$ is involved in atherogenesis and ICAM-1 expression in vascular endothelial cells (27). $\mathrm{LTB}_{4}$ is reported to promote atherogenesis by inducing MCP-1 production $(28,29)$. 15-HETrE has antiinflammatory properties and has been suggested to exert further anti-inflammatory effects by inhibiting 5-lipoxygenase, an enzyme that converts arachidonic acid into inflammatory eicosanoids (30). The antiatherosclerotic effects of DGLA have been previously reported (31), and a DGLA-derived eicosanoid, $\mathrm{PGE}_{1}$, is thought to be the key to antiatherosclerotic effects. $\mathrm{PGE}_{1}$ has been reported to reduce ICAM-1 expression in monocytes, resulting in repression of T-cell infiltration under vascular endothelial cells $(32,33)$. Confirming the effects of D5D inhibition on atherosclerotic plaque stabilization should be done in future work by measuring the pathophysiological changes in plaque composition. Taken together, the present results suggest that reduced levels of pro-inflammatory eicosanoids and increased levels of antiinflammatory eicosanoids exert anti-inflammatory impact, resulting in anti-atherosclerotic effects by D5D inhibition.

In the post-treatment protocol study, treatment of compound-326 did not reduce the $\mathrm{LTB}_{4}$ production despite of the significant reduction in the liver AA content and in the production of $\mathrm{PGE}_{2}$ and $\mathrm{TXB}_{2}$ (Figure 2). This result shows a clear difference from our previous pre-treatment protocol study (8) and current Paigen diet-study (Figure 6), which indicated concurrent decreases in the liver $\mathrm{AA}$ content and in the production of $\mathrm{PGE}_{2}, \mathrm{TXB}_{2}$ and $\mathrm{LTB}_{4}$. Interestingly, several studies reported that long-term high fat diet feeding enhances the expression of 5-lipoxygenase (5-LO) and 5-LOactivating protein $(34,35)$. In the future, it may be interesting to investigate whether the long-term high fat diet feeding may change the balance between $\mathrm{LTB}_{4}$-generating 5-LO pathway and $\mathrm{PGE}_{2} / \mathrm{TXB}_{2}$ generating cyclooxygenase-2 (COX-2) pathways in ApoE knockout mice, where the 5-LO pathways is known to be activated (36).

Compound-326 reduced plasma sICAM-1 levels without altering plasma cholesterol levels in ApoE knockout mice with both protocols, indicating 
that D5D inhibition can potentially exert antiinflammatory action. Plasma sICAM-1 levels are a marker of vascular inflammation and a risk factor for cardiovascular diseases $(37,38)$. Plasma sICAM-1 levels also can predict future cardiovascular events (39). One report suggested that high levels of plasma sICAM-1 correlate with a poor prognosis (40). Regarding the plasma MCP-1 level reduction observed in the Paigen diet protocol, several reports have suggested a relationship between plasma MCP1 concentrations and atherosclerosis $(41,42)$. The anti-inflammatory properties of D5D inhibitors, which are independent of plasma cholesterol levels, can realize further benefits in treating atherosclerosis in addition to statins, the standard treatment (2).

Suppressive effects of D5D inhibition on body weight gain independent of food intake were also confirmed in both protocols in this study, indicating a beneficial and advantageous aspect of D5D inhibitors. Since D5D inhibition does not alter body weight in normal chow-fed conditions, it is likely that D5D inhibition results in fat mass gain reduction (8). Several reports refer to the contribution of chronic inflammation to insulin resistance and related metabolic disorders $(43,44)$. Previous studies have suggested that D5D inhibition can exert antiobesity and anti-diabetic effects, accompanied by fat reduction $(7,8,15)$. The study of Yashiro et. al. (15) reported that treatment of compound-326 in dietinduced obese C57BL/6J mice decreased expression of macrophage-related inflammatory genes in adipose tissues and increased the whole-body energy expenditure, which effects could account for the antiobesity effects of compound-326. Further analysis should, however, be needed to clarify the underlying mechanisms.

An increase in hepatic TG was observed in the Paigen diet protocol, although it was within the normal range (under $50 \mu \mathrm{g} / \mathrm{mg}$ ). Plasma ALT were not concurrently increased, suggesting that the increase in the hepatic TG is a physiological but not a pathological change. Our preliminary studies indicate that this hepatic TG increase is observed under specific conditions and depends on diet composition and duration. In fact, the hepatic TG increase was not observed in the present posttreatment protocol. Some studies have suggested that increased lipogenesis related to polyunsaturated fatty acid-mediated regulation of SREBP-1c may be a potential mechanism underlying this phenomenon. Moon et al. (2009) reported that SREBP-1c positively regulated the expression of genes involved in the synthesis of free fatty acid from citrate, and that polyunsaturated fatty acid negatively regulated
SREBP-1c expression. Since D5D catalyzes the formation of arachidonic acid, eicosapentaenoic acid, and the downstream product docosahexaenoic acid, which are all polyunsaturated fatty acids (45), inhibiting D5D may attenuate the suppression of SREBP-1c by these polyunsaturated fatty acids, resulting in increased fatty acid and eventual TG synthesis in hepatocytes. This may be a limited effect only in animal experiments since diets we used in this study contain poor polyunsaturated fatty acids, unlike clinical situation with exogenous polyunsaturated fatty acid consumption. Future work should elucidate the mechanism underlying this effect, including whether a similar phenomenon occurs in humans.

\section{CONCLUSION}

In conclusion, the findings of the present study clearly indicate that compound-326 exerts antiatherosclerotic effects accompanied by antiinflammatory action in ApoE knockout mice with two different protocols for atherosclerosis development, supporting D5D inhibition as a promising strategy in treating atherosclerosis.

\section{CONFLICT OF INTEREST}

The authors declare that they have no conflict of interest.

\section{ACKNOWLEDGEMENT}

We are grateful to Dr. Masakuni Noda for guidance and helpful comments during the conduct of this study. We would like to acknowledge all the Takeda D5D project members, especially Hiromi Shinohara, Hideo Suzuki, Takuya Fujimoto, Takeshi Yamamoto, Hidenori Kamiguchi, and Nobuhiro Nishigaki. We also would like to thank Editage (www.editage.jp) for English language editing.

\section{REFERENCES}

1. Mackay J, Mensah G. Atlas of heart disease and stroke. World Health Organization; 2004 Jan:84-91.

2. Roger VL, Go AS, Lloyd-Jones DM, et al. Heart disease and stroke statistics--2012 update: A report from the American Heart Association. Circulation. 2012;125(1):e12-e220. https://doi.org/10.1161/cir.0b013e31823ac046

3. Libby P. Inflammation in atherosclerosis. Nature. 2002;420(6917):868-874.

https://doi.org/10.1038/nature01323 
4. Ridker PM, Everett BM, Thuren $\mathrm{T}$, et al. Antiinflammatory Therapy with Canakinumab for Atherosclerotic Disease. N Engl J Med. 2017;377(12):1119-1131.

https://doi.org/10.1056/nejmoa1707914

5. Charo IF, Taub R. Anti-inflammatory therapeutics for the treatment of atherosclerosis. Nat Rev Drug Discov. 2011;10(5):365-376.

6. https://doi.org/10.1038/nrd3444

7. Libby P, Aikawa M. Stabilization of atherosclerotic plaques: new mechanisms and clinical targets. Nat Med. 2002;8(11):1257-1262.

8. https://doi.org/10.1038/nm1102-1257

9. Powell DR, Gay JP, Smith M, et al. Fatty acid desaturase 1 knockout mice are lean with improved glycemic control and decreased development of atheromatous plaque. Diabetes Metab Syndr Obes. 2016;9:185-199.

https://doi.org/10.2147/dmso.s106653

10. Takagahara S, Shinohara H, Itokawa S, et al. A Novel Orally Available Delta-5 Desaturase Inhibitor Prevents Atherosclerotic Lesions Accompanied by Changes in Fatty Acid Composition and Eicosanoid Production in ApoE Knockout Mice. J Pharmacol Exp Ther. 2019;371(2):290-298. https://doi.org/10.1124/jpet.119.259846

11. Cho HP, Nakamura M, Clarke SD. Cloning, expression, and fatty acid regulation of the human delta-5 desaturase. J Biol Chem. 1999;274(52):37335-37339.

https://doi.org/10.1074/jbc.274.52.37335

12. Matsuzaka T, Shimano H, Yahagi N, et al. Dual regulation of $\square^{5}$ - and $\square{ }^{6}$-desaturase gene expression by SREBP-1 and PPAR $\square$. J Lipid Res. 2002;43(1):107-114.

13. Leonard AE, Kelder B, Bobik EG, et al. cDNA cloning and characterization of human Delta5desaturase involved in the biosynthesis of arachidonic acid. Biochem J. 2000;347:719-724.

14. De Caterina R, Zampolli A. From asthma to atherosclerosis- 5-lipoxygenase, leukotrienes, and inflammation. N Engl J Med. 2004:350(1):4-7. https://doi.org/10.1056/nejmp038190

15. Kwak JH, Paik JK, Kim OY, et al. FADS gene polymorphisms in Koreans: association with $\omega 6$ polyunsaturated acids in serum phospholipids, lipid peroxides, and coronary artery disease. Atherosclerosis. 2011;214(1):94-100. https://doi.org/10.1016/j.atherosclerosis.2010.10.00 4

16. Martinelli N, Girelli D, Malerba G, et al. FADS genotypes and desaturase activity estimated by the ratio of arachidonic acid to linoleic acid are associated with inflammation and coronary artery disease. Am J Clin Nutr. 2008;88(4):941-949. https://doi.org/10.1093/ajcn/88.4.941

17. Yashiro H, Takagahara S, Tamura YO, et al. A novel selective inhibitor of delta-5 desaturase lowers insulin resistance and reduces body weight in dietinduced obese C57BL/6J mice. PLoS One. 2016;11(11):e0166198. https://doi.org/10.1371/journal.pone.0166198

18. Getz GS, Reardon CA. Diet and murine atherosclerosis. Arterioscler Thromb Vasc Biol. 2006;26(2):242-249. https://doi.org/10.1161/01.atv.0000201071.49029.1 7

19. Nakashima Y, Plump AS, Raines EW, et al. ApoEdeficient mice develop lesions of all phases of atherosclerosis throughout the arterial tree. Arterioscler Thromb. 1994;14(1):133-140. https://doi.org/10.1161/01.atv.14.1.133

20. Paigen B. Genetics of responsiveness to high-fat and high-cholesterol diets in the mouse. Am J Clin Nutr. 1995;62(2):458S-462S. https://doi.org/10.1093/ajcn/62.2.458s

21. Jawien J, Nastalek P, Korbut R. Mouse models of experimental atherosclerosis. J Physiol Pharmacol. 2004;55(3):503-517.

22. Veillard NR, Steffens S, Burger F, et al. Differential expression patterns of proinflammatory and antiinflammatory mediators during atherogenesis in mice. Arterioscler Thromb Vasc Biol. 2004;24(12):2339-2344. https://doi.org/10.1161/01.atv.0000146532.98235.e 6

23. Lusis AJ. Atherosclerosis. Nature. 2000;407(6801):233-241. https://doi.org/10.1038/35025203

24. Ross R. Atherosclerosis--an inflammatory disease. $\mathrm{N}$ Engl J Med. 1999;340(2):115-126. https://doi.org/10.1056/nejm199901143400207

25. Libby P, Ridker PM, Maseri A. Inflammation and atherosclerosis. Circulation. 2002;105(9):11351143. https://doi.org/10.1161/hc0902.104353

26. Puntmann VO, Bigalke B, Nagel E. Characterization of the inflammatory phenotype in atherosclerosis may contribute to the development of new therapeutic and preventative interventions. Trends Cardiovasc Med. 2010;20(5):176-181. https://doi.org/10.1016/j.tcm.2011.03.001

27. Agren JJ, Julkunen A, Penttila I. Rapid separation of serum lipids for fatty acid analysis by a single aminopropyl column. J Lipid Res. 1992;33(12):1871-1876.

28. Babaev VR, Chew JD, Ding L, et al. Macrophage EP4 deficiency increases apoptosis and suppresses 
early atherosclerosis. Cell Metab. 2008;8(6):492501. https://doi.org/10.1016/j.cmet.2008.09.005

29. Kobayashi T, Tahara Y, Matsumoto M, et al. Roles of thromboxane A (2) and prostacyclin in the development of atherosclerosis in apoE-deficient mice. J Clin Invest. 2004;114(6):784-794. https://doi.org/10.1172/jci21446

30. Heller EA, Liu E, Tager AM, et al. Inhibition of atherogenesis in BLT1-deficient mice reveals a role for LTB4 and BLT1 in smooth muscle cell recruitment. Circulation. 2005;112(4):578-586. https://doi.org/10.1161/circulationaha.105.545616

31. Subbarao K, Jala VR, Mathis S, et al. Role of leukotriene B4 receptors in the development of atherosclerosis: potential mechanisms. Arterioscler Thromb Vasc Biol. 2004;24(2):369-375. https://doi.org/10.1161/01.atv.0000110503.16605.1 5

32. Ziboh VA, Miller CC, Cho Y. Metabolism of polyunsaturated fatty acids by skin epidermal enzymes: generation of antiinflammatory and antiproliferative metabolites. Am J Clin Nutr. 2000;71(1 Suppl):361S-366S. https://doi.org/10.1093/ajen/71.1.361s

33. Takai S, Jin D, Kawashima $\mathrm{H}$, et al. Antiatherosclerotic effects of dihomo- $\gamma$-linolenic acid in ApoE-deficient mice. J Atheroscler Thromb. 2009;16(4):480-489.

https://doi.org/10.5551/jat.no430

34. Palumbo B, Oguogho A, Fitscha $P$, et al. Prostaglandin E1-therapy reduces circulating adhesion molecules (ICAM-1, E-selectin, VCAM1) in peripheral vascular disease. Vasa. 2000;29:179-185. https://doi.org/10.1024/03011526.29.3.179

35. Takahashi HK, Iwagaki H, Tamura R, et al. Unique regulation profile of prostaglandin $\mathrm{E} 1$ on adhesion molecule expression and cytokine production in human peripheral blood mononuclear cells. J Pharmacol Exp Ther. 2003;307(3):1188-1195. https://doi.org/10.1124/jpet.103.056432

36. Wang X, Lin Y, Luo N, et al. Short-term intensive atorvastatin therapy improves endothelial function partly via attenuating perivascular adipose tissue inflammation through 5-lipoxygenase pathway in hyperlipidemic rabbits. Chin Med J (Engl). 2014;127(16):2953-9.

37. Darrow AL, Shohet RV, Maresh JG. Transcriptional analysis of the endothelial response to diabetes reveals a role for galectin-3. Physiol Genomics. 2011;43(20):1144-52.

https://doi.org/10.1152/physiolgenomics.00035.201 1
38. Martínez-Clemente M, Ferré N, González-Périz A, et al. 5-lipoxygenase deficiency reduces hepatic inflammation and tumor necrosis factor alphainduced hepatocyte damage in hyperlipidemiaprone ApoE-null mice. Hepatology. 2010;51(3):817-27. https://doi.org/10.1002/hep.23463

39. Witkowska AM. Soluble ICAM-1: a marker of vascular inflammation and lifestyle. Cytokine. 2005;31(2):127-134. https://doi.org/10.1016/j.cyto.2005.04.007

40. Nguyen QM, Srinivasan SR, Xu JH, et al. Distribution and cardiovascular risk correlates of plasma soluble intercellular adhesion molecule-1 levels in asymptomatic young adults from a biracial community: the Bogalusa Heart Study. Ann Epidemiol. 2010;20(1):53-59. https://doi.org/10.1016/j.annepidem.2009.10.001

41. Marcinkowski M, Czarnecka D, Jastrzebski M, et al. Inflammatory markers 10 weeks after myocardial infarction predict future cardiovascular events. Cardiol J. 2007;14(1):50-58.

42. Rallidis LS, Zolindaki MG, Vikelis $\mathrm{M}$, et al. Elevated soluble intercellular adhesion molecule-1 levels are associated with poor short-term prognosis in middle-aged patients with acute ischaemic stroke. Int J Cardiol. 2009;132(2):216-220. https://doi.org/10.1016/j.ijcard.2007.11.031

43. Aiello RJ, Bourassa PA, Lindsey S, et al. Monocyte chemoattractant protein-1 accelerates atherosclerosis in apolipoprotein E-deficient mice. Arterioscler Thromb Vasc Biol. 1999;19(6):15181525. https://doi.org/10.1161/01.atv.19.6.1518

44. Ni W, Egashira K, Kitamoto S, et al. New antimonocyte chemoattractant protein-1 gene therapy attenuates atherosclerosis in apolipoprotein Eknockout mice. Circulation. 2001;103(16):20962101. https://doi.org/10.1161/01.cir.103.16.2096

45. Khodabandehloo H, Gorgani-Firuzjaee S, Panahi G, et al. Molecular and cellular mechanisms linking inflammation to insulin resistance and $\beta$-cell dysfunction. Transl Res. 2016;167(1):228-256. https://doi.org/10.1016/j.trsl.2015.08.011

46. Welty FK, Alfaddagh A, Elajami TK. Targeting inflammation in metabolic syndrome. Transl Res. 2016;167(1):257-280. https://doi.org/10.1016/j.trsl.2015.06.017

47. Moon YA, Hammer RE, Horton JD. Deletion of ELOVL5 leads to fatty liver through activation of SREBP-1c in mice. J Lipid Res. 2009;50(3):412423. https://doi.org/10.1194/jlr.m800383-jlr200 